DOI: $10.17957 / \mathrm{IJAB} / 15.1666$

http://www.fspublishers.org

\title{
Marigold (Tagete erecta): An Effective Meloidogyne incognita Trap Plant
}

\author{
Wentao $\mathrm{Wu}^{\dagger}$, Ying Dong ${ }^{\dagger}$, Yong Xie, Meijing Xue, Jing Zhang, Huanyu Wei, Guanghai Ji* and Yang Wang* \\ State Key Laboratory for Conservation and Utilization of Bio-Resources in Yunnan, Yunnan Agricultural University, Kunming, \\ 650201, China \\ For correspondence: jghai001@aliyun.com; wangyang626@sina.com \\ Contributed equally to this work and are co-first authors \\ Received 21 July 2020; Accepted 15 October 2020; Published 10 January 2021
}

\begin{abstract}
Root-knot nematodes (Meloidogyne spp.) are soil-borne pathogens that can cause severe damage to agricultural production. The most common approaches to prevent root-knot nematode infections are based on crop rotation with non-host plants, use of chemical insecticides, biological control methods, and use of nematode-antagonistic or trap plants. Marigolds (Tagetes erecta) are used as nematode-killing plants, but there is controversy over the mechanism through which they control root-knot nematodes. This study confirmed that marigold root-exudates are lethal to root-knot nematodes, illustrated that marigolds act as trap plants for root-knot nematodes when planted close to nematode host plants such as tomato. We investigated the rates of infection and development of nematode larvae injected into the marigold root system to evaluate whether marigolds could act as a non-host plant for root-knot nematodes. We found that aqueous solutions of marigold root-exudates showed strong lethal and inhibitory effects on sec-stage juveniles and eggs of root-knot nematodes. Marigold roots secreted substances that attracted nematodes from the surrounding environment. Furthermore, marigold root cells contained substances that had a strong inhibitory effect on the development of root-knot nematodes, resulting in diapause in nematodes, and inhibition of further infection. Herein we report a preliminary exploration of the antagonistic mechanism in marigolds for controlling the growth and development of root-knot nematodes. Our research provides basis for promoting the use of marigold for the control of nematodes as an important part of sustainable cropping strategies that rely on biological pest control. (C) 2021 Friends Science Publishers
\end{abstract}

Keywords: Tagetes erecta; Meloidogyne spp.; Root exudates; Tropism; Diapause

\section{Introduction}

Root-knot nematodes (Meloidogyne spp.) are plant pathogens that are harmful to many globally important agricultural crops. These nematodes have a wide variety of host plants, and a strong reproductive and adaptive capability that makes them a serious threat to global food security. Root-knot nematodes can damage plants via two pathways. First, parasitic root-knot nematodes directly destroy plant roots and prevent the transport of nutrients in host plants. Sec, the wounds they cause in host roots are subject to infection by bacteria, viruses, and fungi, which can result in composite diseases (Ingels et al. 1998). Infection by rootknot nematodes has multiple direct and indirect effects, thereby hampering damage identification and control. Since resistant plant varieties are limited, and the use of soil fumigants and chemically active ingredients that are lethal to nematodes is restricted due to their direct toxicity to humans and to the environment, it is difficult to prevent and control nematode infections in host plants. As such, research studies have focused on the use of nematode-antagonistic plants to control root-knot nematodes, with the aim of developing nematode management strategies that are economically feasible, non-polluting, and thus, sustainable. Since the 1980s, more than 100 types of plants from over 40 families have been reported to have lethal effects on nematodes (Gowen 2002) and more than 100 substances with lethal effects on nematodes have been extracted from these plants (Chitwood 2002). In fact, some of these substances are now commercially available.

Marigold (Tagetes erecta), a plant species native to Mexico, is an annual herbaceous flower in the Asteraceae family, and a member of genus Tagetes, which was one of the first used as a nematode antagonist (Steiner 1941). Numerous approaches using marigolds have been developed for the control of root-knot nematodes (Hooks et al. 2010). These include using the allelochemicals secreted by marigold roots (Marles et al. 1992), using marigolds as a cover crop (Ploeg 2002), extracting substances from marigolds (Hagag et al. 2016), or using marigolds as a non-host plant against root-knot nematodes (López-Pérez et al. 2010).

However, there is still much controversy over the use

To cite this paper: Wu W, Y Dong, Y Xie, M Xue, J Zhang, H Wei, G Ji, Y Wang (2021). Marigold (Tagete erecta): an effective Meloidogyne incognita trap plant. Intl J Agric Biol 25:271-276 
of marigolds to control root-knot nematodes. Some studies proposed that, among secreted allelochemicals, terthiophene is the primary substance that is lethal to nematodes in marigolds, but Marles et al. (1992) applied a mixture of terthiophene to soils and found no lethal effects on nematodes. Thiophenes are non-polar compounds, but many activity trials performed on nematodes with extracts from marigolds used aqueous extracts (Siddiqui and Mashkoor 1988; Natarajan et al. 2006), which might have severely limited the extracts' effectiveness in soil trials. Crop rotation of tomato (Solanum lycopersicum) plants with marigold plants may decrease nematode infection in tomato plants, and increase yield of rotated tomato crops compared to that without rotation. However, planting of marigolds after fallowing failed to decrease the number of southern root-knot nematodes, Meloidogyne incognita (Marahatta et al. 2012).

In the present study, we investigated the mechanism by which marigolds control root-knot nematodes. We aimed to determine whether root-exudates from marigolds could have lethal effects on nematodes, and whether marigold rootexudates could attract root-knot nematodes. Furthermore, we aimed to determine whether marigolds could be a type of non-parasitic plant for root-knot nematodes. The information obtained here might improve the use of marigolds in the control of root-knot nematodes in agricultural fields. The attraction and trapping effects of the marigold root-exudates on sec-stage nematode juveniles were examined by comparing the tropism of sec-stage juveniles in relation to roots of marigolds and host plants of root-knot nematodes. We also evaluated whether marigolds could be a non-host plant for root-knot nematodes by inoculating marigold plants with sec-stage juveniles at $25^{\circ} \mathrm{C}$, and observing their development and infection rate in marigold roots.

\section{Materials and Methods}

\section{Purification and maintenance breeding of root-knot nematodes}

Meloidogyne incognita was used in this experiment. Light yellow, large, and plump single egg masses were selected under a dissecting microscope from the root knots of infected 'Rutgers' tomato plants, and inoculated on the young roottips of susceptible tomato plants ('Rutgers;' laboratory preserved) pre-cultivated in sterilised pots and soil (sand: humic soil $=1: 1$ ) at the 4-5 true leaf-bearing stage. Three holes were dig near each plant and filled with $M$. incognita eggs incubated at room temperature $\left(28^{\circ} \mathrm{C}\right)$ for $6-8$ weeks.

\section{Collection of root-knot nematode eggs and collection of sec-stage juveniles}

Roots containing root-knots were selected, and the surface soil on them was washed off before they were cut into 1-2 $\mathrm{cm}$ segments. These segments were then placed in a beaker filled with $200 \mathrm{~mL}$ of $0.525 \% \mathrm{NaClO}$ solution, and vigorously stirred for 2-4 min. The stirred mixture was immediately poured onto a set of sieves ( $74 \mu \mathrm{m}$ and $30 \mu \mathrm{m})$. The eggs collected on the $74 \mu \mathrm{m}$ sieve were thoroughly rinsed with tap water, followed by collection of the eggs from the $30 \mu \mathrm{m}$ sieve, which were then placed in Petri dishes. After $48 \mathrm{~h}$ incubation at $25^{\circ} \mathrm{C}$, the eggs hatched into sec-stage juveniles, which were collected using the same suite of sieves (74 $\mu \mathrm{m}$ and $30 \mu \mathrm{m})$.

\section{Preparation of plant materials}

Marigold and tomato seeds were soaked in $10 \% \mathrm{NaClO}$ solution for 20-30 min and then placed on wet filter paper for germination in a thermostatic chamber at $28^{\circ} \mathrm{C}$. After germination, the seeds were planted in sterilized soil packed into sterilized pots (sand: humic soil =1:1). Plants were cultivated at $28^{\circ} \mathrm{C}$ and $70 \%$ relative humidity until use, both carefully controlled in a greenhouse.

\section{Lethal effects of marigold root-exudates on nematodes}

Collection of marigold root exudates: Root exudates were collected according to the method developed by Tang and Young (1982). Robust and similar marigold plants at the 7 leaf stage were planted and cultivated in a collection device (which formed part of a hydroponic system with an airlift pump for circulation), to which $2 \mathrm{~L}$ of distilled water were added. The solution was circulated at a rate of $1 \mathrm{~L} / \mathrm{h}$ of airlifting. Distilled water was replenished twice daily to compensate for transpiration- and evaporation-related loss. After $7 \mathrm{~d}$ in the presence of a circulated and recycled nutrient solution, the collection devices were dismantled and eluted with methanol to collect the root exudate material. The effluent was transferred to a rotary evaporator for drying, and the dry materials were collected and weighed.

Measurement of lethal effects of marigold-root exudates on root-knot nematodes and inhibition of egg hatching: The lethal and inhibitory activities of the collected marigold root-exudates on sec-stage root-knot nematode juveniles and egg hatching, respectively, were measured as follows. A series of aqueous solutions of root-exudates was prepared $(52.5,105,210,525,1050,1400,2100$ and $4200 \mu \mathrm{g} / \mathrm{mL})$ in 60-mm diameter watch glasses. To each watch glass, $3 \mathrm{~mL}$ of a solution containing $100 \mathrm{sec}$-stage juvenile $M$. incognita or 200 eggs of the nematodes was added; each treatment was run in triplicate. Distilled water was used in the control groups $(\mathrm{n}=3)$. The watch glasses were placed in a thermostatic chamber at $28^{\circ} \mathrm{C}$, and after $4 \mathrm{~h}, 12 \mathrm{~h}, 24 \mathrm{~h}$, and $48 \mathrm{~h}$, the mortality rate of sec-stage juveniles was examined under a microscope. Sec-stage juveniles were allowed to rest in water for $2 \mathrm{~h}$; after this period, the sec-stage juveniles treated with $525 \mu \mathrm{g} / \mathrm{mL}$ of root-exudates were found to be all dead by observing the state of the nematode in clear water after $2 \mathrm{~h}$. Mortality and corrected mortality rates were calculated for each treatment. Corrected mortality rate $=$ (treatment group nematode mortality rate - control group nematode mortality rate $) /(1$ - control group nematode mortality rate) $\times 100 \%$. The inhibition rate of egg hatching 
was observed daily for $6 \mathrm{~d}$.

\section{Root-knot nematode tropism in the presence of marigold roots}

Preparation of 23\% Pluronic F-127 sol-gel: For this experiment, the sand used in the 6 arm inducing device designed by Gao et al. (2008) was replaced with $23 \%$ Pluronic F-127 sol-gel, where nematodes could move freely. One hundred millilitres of $23 \%$ Pluronic F-127 sol-gel was prepared by adding $23 \mathrm{~g}$ of Pluronic F-127 to $80 \mathrm{~mL}$ of sterilized water chilled to $4^{\circ} \mathrm{C}$. This mixture was stirred for $24 \mathrm{~h}$, and $10 \mathrm{~m} M$ sodium phosphate was used to adjust the $\mathrm{pH}$ to 7.0. The prepared sol-gel was stored at $15^{\circ} \mathrm{C}$ until use (Wang et al. 2009).

Qualitative study of root-knot nematodes tropisms in the presence of marigold roots: Pluronic F-127 sol-gel ( $20 \mathrm{~mL}$ ) was added to a $60-\mathrm{mm}$ diameter Petri dish. Subsequently, four root tips from cultivated marigold and tomato plants were placed in opposite ends of the Petri dish. After the sol-gel solidified, 1000 sec-stage juveniles of $M$. incognita were placed at the centre of the Petri dish. Petri dishes were observed every $2 \mathrm{~h}$, and $17 \mathrm{~h}$ after inoculation, the sec-stage juvenile root-knot nematodes in the Petri dish were photographed under an inverted microscope to observe their directional movement. This experiment was repeated thrice.

Quantitative study on root-knot nematode tropism in response to marigold roots: A 6-arm nematode-trapping device designed and constructed by our research group to facilitate the quantitative analysis of nematode tropism was used to quantify the capability of marigold root-tips to attract root-knot nematodes. This device is schematically illustrated in Fig. 1: Marigold and tomato plant roots were placed in black plastic tubes (2); black plastic tubes (2) containing plants, were inserted into the holes on the wall of a transparent, uncovered cylindrical container (1); at a temperature below $15^{\circ} \mathrm{C}$, the cylindrical container (1) and black plastic tubes (2) were completely filled with $23 \%$ Pluronic F-127 sol-gel; The device was placed at ambient temperature $\left(28^{\circ} \mathrm{C}\right)$. After the sol-gel solidified, 3,000 secstage $M$. incognita juveniles were placed at the centre of the container (1); after 24 or $48 \mathrm{~h}$, the black plastic tubes (2) were dismounted and placed in a labelled Petri dish at $4^{\circ} \mathrm{C}$ to allow the sol-gel to soften; The Petri dishes were allowed to settle for 10-20 min; The number of $M$. incognita root-knot nematodes in each Petri dish was observed under an inverted microscope.

Inoculation and observation of development status in marigold and tomato plants: Marigold and tomato seedlings were transplanted into $20 \mathrm{~cm}$ diameter pots containing sterilized soil (humic soil: sand $=1: 2$ ) inoculated with M. incognita. Approximately 3,000 nematodes were used to inoculate each pot. Three biological and three technical repeats were performed for each treatment. At 2, 4, 8,16 , and $30 \mathrm{~d}$ after inoculation, the roots of six plants were rinsed with water before tissue staining to determine the infection rates and developmental status of $M$. incognita in the inoculated roots.

Marigold and tomato roots were rinsed with water, dried with absorbent paper, and cut into 1-2 $\mathrm{cm}$ segments. These segments were soaked in $100 \mathrm{~mL} 1.5 \% \mathrm{NaClO}$ solution, stirred for $4 \mathrm{~min}$, flushed with water on a $74 \mu \mathrm{m}$ sieve for $30 \mathrm{~s}$, soaked in $150 \mathrm{~mL}$ tap water for $15 \mathrm{~min}$, and then boiled in $12.5 \%$ commercially available red food dye for $30 \mathrm{~s}$ (Thies et al. 2002). After cooling to room temperature $\left(28^{\circ} \mathrm{C}\right)$, the root-dye mixture was transferred onto a $74 \mu \mathrm{m}$ sieve, and additionally rinsed with tap water. These rinsed roots were added to pre-warmed acidic glycerol $\left(40^{\circ} \mathrm{C}\right)$ and stirred for $15 \mathrm{~s}$, cooled to room temperature $\left(28^{\circ} \mathrm{C}\right)$, and finally placed between two microscope slides $(5$ $\mathrm{cm} \times 12 \mathrm{~cm}$ ) and observed under a dissecting microscope to assess the developmental status of the nematodes that invaded roots and to calculate the infection percentage. Data were analysed using MS Excel.

\section{Results}

\section{Measurement of lethal effects of marigold root exudates on nematodes}

Marigold root-exudates were collected for $6 \mathrm{~d}$ using a circulation and recycling device, and eluted from the resin columns with methanol. The dried effluent was dissolved in $1 \mathrm{~mL}$ sterile water; eight concentrations of the effluent, from 52.5 to $4,200 \mu \mathrm{g} / \mathrm{mL}$, were used for the experiment. Marigold root-exudates in eight different concentrations had a strong lethal effect on the nematodes (Fig. 2). At concentrations of $525,1,050,2,100$, and $4,200 \mu \mathrm{g} / \mathrm{mL}$, almost all the nematodes died within $4 \mathrm{~h}$ of exposure to marigold rootexudates. Thus, these concentrations were not used for further analyses. Marigold root-exudates had a lethal effect on sec-stage juvenile nematodes that was dose-dependent at concentrations of 210, 105, and $52.5 \mu \mathrm{g} / \mathrm{mL}$ (Fig. 2). Furthermore, corrected mortality increased with longer exposure to the exudate solutions (Fig. 2).

At $105 \mu \mathrm{g} / \mathrm{mL}$, the root-exudates killed $50 \%$ of the secstage juveniles within $4 \mathrm{~h}$, and the corrected mortality was $57.3,61.4$ and $66.6 \%$ within 12,24 , and $48 \mathrm{~h}$, respectively. At a concentration of $52.5 \mu \mathrm{g} / \mathrm{mL}$, the corrected mortality of root-knot nematode sec-stage juveniles was 6.3, 3.1, 2.1 and $1.5 \%$ at $4,12,24$, and $48 \mathrm{~h}$, respectively, indicating that the corrected mortality did not significantly increase over time. Furthermore, these mortality values were not significantly different from those of the control group, suggesting that marigold root-exudates did not have a lethal effect on secstage juvenile root-knot nematodes at concentrations below $52.5 \mu \mathrm{g} / \mathrm{mL}$.

Inhibitory effect of marigold root-exudates on root-knot nematode egg hatching

The inhibitory effect of marigold root-exudates at 210, 105 
and $52.5 \mu \mathrm{g} / \mathrm{mL}$ on root-knot nematode egg hatching was measured in the laboratory. Egg hatching was observed daily for $6 \mathrm{~d}$. The results indicated that root-exudates had a very strong inhibitory effect on egg hatching (Fig. 3). Exposure to exudate concentrations of 210 and $105 \mu \mathrm{g} / \mathrm{mL}$, the hatching rate did not show obvious changes, and after $6 \mathrm{~d}$, the maximum hatching rate was 4 and $8 \%$, respectively, indicating that these two root exudate concentrations had very strong inhibitory effects on the egg hatching rates of root-knot nematodes. When the concentration of marigold root exudates was $52.5 \mu \mathrm{g} / \mathrm{mL}$, the egg hatching rate after $6 \mathrm{~d}$ was $53 \%$, in contrast to $72 \%$ in the control group. These results indicated that nematode egg hatching was not significantly affected by root-exudates at this low concentration.

\section{Sec-stage root-knot nematodes tropism in response to plant roots}

Qualitative study of the tropism of root-knot sec-stage juvenile nematodes in response to marigold and tomato plant roots: After $12 \mathrm{~h}$, a large number of sec-stage juvenile root-knot nematodes accumulated around the root tips of marigolds, whereas no accumulation was observed around the root tips of tomato plants (Fig. 4). This observation suggested that the root system of marigolds could secrete a substance that was attractive to the sec-stage juveniles leading to the accumulation of root-knot nematodes around marigold roots.

Quantitative study of sec-stage juvenile nematode tropism in response to marigold and tomato plant roots: Tomato and marigold roots were removed from the device, and juvenile nematodes were counted under a dissecting microscope to evaluate the difference between the attraction exerted by marigold and tomato roots (Fig. 5). After $24 \mathrm{~h}$, marigold and tomato plants had attracted 25.1 and 12.6 nematodes, respectively; after $48 \mathrm{~h}$, these numbers increased to 34.6 and 56.0, respectively. Thus, the number of nematodes around marigold roots was higher than that around tomato roots at the earlier time point; however, after $48 \mathrm{~h}$, the number of nematodes around tomato roots was higher than around marigold roots. Root staining showed that, at $12 \mathrm{~h}$, no sec-stage juveniles were found either in marigold or tomato roots; or at $24 \mathrm{~h}$, almost no sec-stage juveniles were found in the marigold or tomato roots; therefore, no statistical analysis could be conducted. These results indicated that marigold roots secreted a substance that effectively attracted root-knot nematodes. However, the effect of this substance decreased over time in the presence of tomato plants.

\section{Infection rates and developmental status of nematodes in marigold and tomato plant roots}

Staining of root tissues helped reveal that the infection rate of root-knot nematodes in the marigold roots gradually increased from 2 to $8 \mathrm{~d}$ after inoculation, peaking at $8 \mathrm{~d}$ with

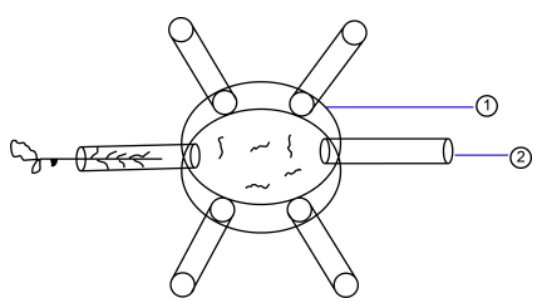

Fig. 1: Schematic representation of the 6-arm nematode-trapping device used in this study

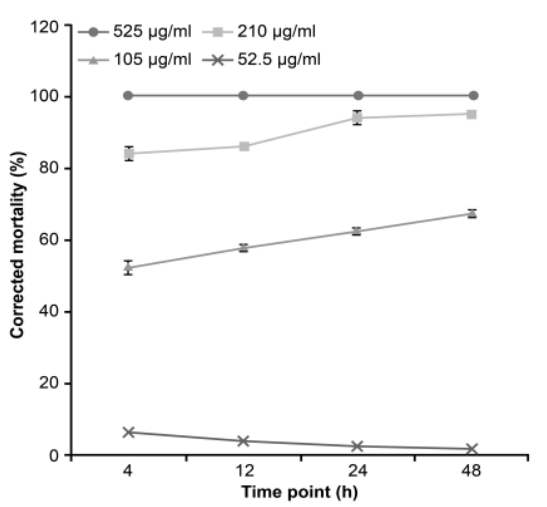

Fig. 2: Effect of different concentrations of marigold rootexudates on Meloidogyne incognita

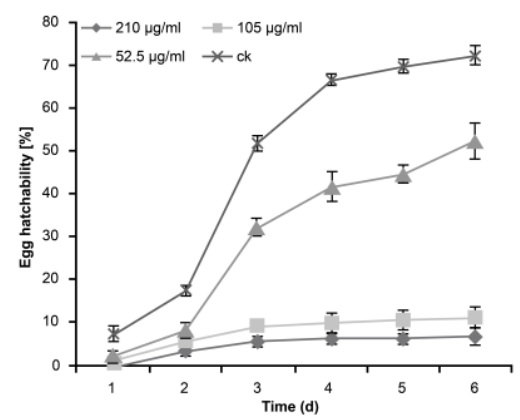

Fig. 3: Inhibitory effect of marigold root-exudates on Meloidogyne incognita egg hatching. $\mathrm{Ck}$ refers to the control treatment

an average of $5.27 \%$. The infection rate gradually dropped from 8 to $30 \mathrm{~d}$, when the root-knot nematodes in the roots accounted for only $2.53 \%$ of the total root-knot nematodes used for inoculation. Staining of tomato root tissues at 2, 4, 8, 16 , and $30 \mathrm{~d}$ after inoculation showed infection rates of 1.5 , $3.35,5.8,18.35$ and $19.2 \%$, respectively, indicating that the infection rate of $M$. incognita in the roots of tomato plants was positively correlated with inoculation time (Fig. 6). During the first $8 \mathrm{~d}$ after inoculation, the infection rate of root-knot nematodes was not significantly different between marigold and tomato plants; however, after $8 \mathrm{~d}$, this was much higher in tomato plants than in marigold plants.

A comparison of the developmental status of root-knot nematodes in the roots of marigold and tomato plants revealed that root-knot nematodes in the roots of marigold 


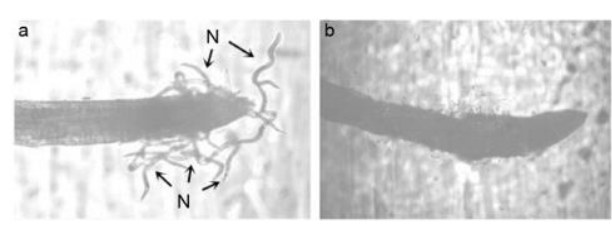

Fig. 4: Tropism of root-knot nematodes in response to root tips. (a) Second-stage juvenile Meloidogyne incognita nematodes (N) clustered around the root tips of marigold plants after $12 \mathrm{~h}$ of cocultivation with tomato and marigold plants. (b) Second-stage juvenile nematodes around the root tips of tomato plants after $12 \mathrm{~h}$ of co-cultivation with tomato and marigold plants

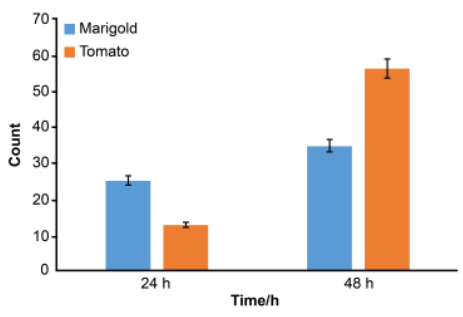

Fig. 5: Comparison of the number of Meloidogyne incognita nematodes attracted to either marigold or tomato roots

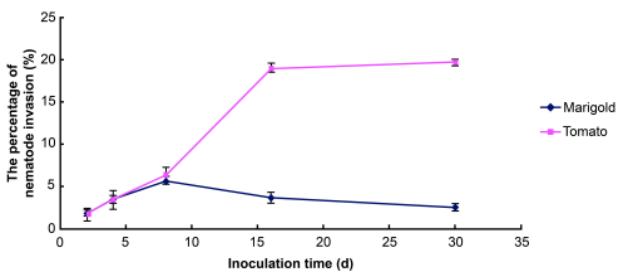

Fig. 6: Infection rates of marigold and tomato roots after inoculation with Meloidogyne incognita

plants were always present as sec-stage juveniles (Fig. 7), whereas, root-knot nematodes in the roots of tomato plants developed normally and became mature females that could lay eggs in $30 \mathrm{~d}$ (Fig. 7).

\section{Discussion}

The lethal effects of marigold plants on nematodes have been studied worldwide. However, the substance characteristic of marigold playing a major role in the lethal effect of rootexudates on nematodes is still a matter of controversy. The results of the present study suggest that this effect is not determined by a single factor, but the result of multiple mechanisms. In the allelopathic phase, some studies have reported that $\alpha$-terthienyl is the main substance that is lethal to nematodes. However, other studies found no significant lethal effects on nematodes when only $\alpha$-terthienyl was applied to the soil. In these particular experiments, the root secretions were collected with water as a solvent, although thiophenes, and in particular thiophenes without substituents, are mostly non-polar compounds. Therefore, it is paradoxical to consider that the active substance in marigolds that is lethal to nematodes is $\alpha$-terthienyl, and it is inferred that $\alpha$ -

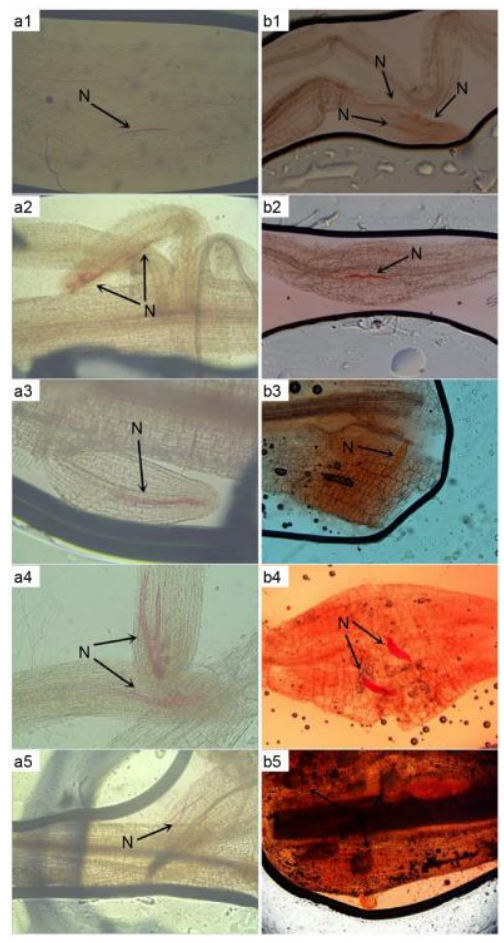

Fig. 7: Developmental status of Meloidogyne incognita $(\mathrm{N})$ at different time points after inoculation in marigold and tomato roots. a1 to a5 indicate the developmental status of root-knot nematodes at 2, 4, 8, 16 and $30 \mathrm{~d}$ after inoculation in marigold roots, respectively. b1 to $\mathbf{b 5}$ indicate the developmental status of root-knot nematodes at 2, 4, 8, 16 and $30 \mathrm{~d}$ after inoculation in tomato roots, respectively

terthienyl is not the only substance produced by marigolds that is lethal to nematodes. In the present study, we found that the secretions from marigold roots could attract root-knot nematodes in the surrounding environment. Thus, marigold roots secrete a substance that can attract nematodes around marigold roots. Intercropping of tomato and crown daisy chrysanthemum (Chrysanthemum coronarium) could reduce the number of root-knot nematodes infecting tomato, because crown daisy chrysanthemum secretes lauric acid and could regulate chemotaxis of sec-stage juveniles (Bais et al. 2006). Furthermore, these compounds could keep nematodes that infect marigold roots in an underdeveloped state. The number of sec-stage juveniles collected from marigold roots was lower than that collected from tomato roots, and marigold root-exudates appeared to have both a dose- and timedependent effect on sec-stage juvenile nematode mortality.

The experimental observations and results reported here suggest that marigold root-exudates and compounds in root tissues play a pivotal role in the ability of marigolds to antagonize root-knot nematodes. The compounds secreted by the roots of marigold plants killed some of the root-knot nematodes, while those that survived and infected the roots were unable to develop normally, to produce offspring to form an effective infection, as shown by the lower developmental status and activity of the nematodes in 
marigold roots than in tomato roots. This was similar to the effects observed for bacteria that can release urea to attract and feed on fungi to form a specific cellular structure that is lethal to nematodes (Wang et al. 2014). Therefore, we hypothesize that marigolds can kill nematodes in the soil through an approach similar to that adopted by "trap" plants.

Root-knot nematodes are dangerous plant pathogens that compromise important agricultural crop species. Using chemical reagents to kill nematodes can result in nematode resistance, as well as in adverse effects on the environment and agricultural production, and on non-target organisms, such as beneficial microorganisms (Goverse and Smant 2014). Therefore, using nematode-antagonistic plants to control these plant parasites is a main method in modern agriculture. During agricultural production, marigolds are used as a cover crop, or alternately planted with other crops to reduce the number of root-knot nematodes in the soil and increase crop production. After harvesting of the target crops, marigolds might be used as green manure to increase soil organic matter content. However, there are still some limitations to the application of marigolds for the control of root-knot nematodes. For example, marigolds may become a host plant for other pests, such as thrips and red spider mites, thereby increasing infection risk for target crops. Crop rotation including marigolds may also decrease the yield of the target crop. Moreover, the ability of marigolds to control root-knot nematodes is related to the variety of marigold used, the root-knot nematode population in the soil, and the local climate conditions (Wang et al. 2007). Therefore, considering local conditions, it is important to select a marigold variety that is effective against the local nematode population, and to employ a proper planting pattern that is optimized for the marigold and crop varieties. When possible, the application of marigolds should be advocated as a nematode-antagonistic strategy.

\section{Conclusion}

The aqueous solution of marigold root exudates had a strong inhibitory effect on the sec instar larvae and eggs of the rootknot nematode, and its lethal concentration to the sec instar larvae is $105 \mu \mathrm{g} / \mathrm{mL}$. when the concentration is higher than $525 \mu \mathrm{g} / \mathrm{mL}$, all the sec instar larvae of the root-knot nematode can be killed within $4 \mathrm{~h}$. When the concentration is 105 $\mu \mathrm{g} / \mathrm{mL}$, the hatching rate of the eggs is only $8 \%$; the roots of marigold can secrete substances that have an attracting effect on nematodes. This study initially explored the antagonistic mechanism of marigold control root-knot nematode disease, which can provide reference for the development and promotion of marigold control and control nematodes.

\section{Acknowledgements}

We gratefully acknowledge funding by the National Natural Science Foundation of China (31560502, 311060361) and National Key R\&D Program of China (2019YFD1002000).

\section{Author Contributions}

Guanghai Ji and Yang Wang conceived and designed research. Wentao Wu and Ying Dong performed the experiments. Yong Xie, Meijing Xue, Jing Zhang and Huanyu Wei prepared the materials. Ying Dong and Wentao $\mathrm{Wu}$ wrote the paper. Guanghai Ji and Yang Wang revised the manuscript. All authors read and approved the final manuscript.

\section{References}

Bais HP, TL Weir, LG Perry, S Gilroy, JM Vivanco (2006). The role of rootexudates in rhizosphere interaction with plants and other organisms. Annu Rev Plant Biol 57:233-266

Chitwood DJ (2002). Phytochemical based strategies for nematode control. Annu Rev Phytopathol 40:221-249

Gao XQ, S James, G Cornelia, J Engelberth, I Feussner, J TumLinson, M Kolomiets (2008). Maize 9-lipoxygenase zmLox3 controls development, root-specific expression of defense genes, and resistance to root-knot nematodes. Mol Plant Microb Interact 21:98-109

Goverse A, G Smant (2014). The activation and suppression of plant innate immunityby parasitic nematodes. Anпu Rev Phytopathol 52:243-265

Gowen SR (2002). Chemical control of nematodes: Efficiency and sideeffects. J Pest Sci 27:65-106

Hagag ESF, NAA Taha, YM Hafez (2016). Control of root-knot nematode (Meloidogyne incognita) on eggplant plants using biotic and abiotic inducers of resistance. Egypt J Biol Pest Contr 26:269-275

Hooks CRR, KH Wang, A Ploeg, R McSorley (2010). Using marigold (Tagetes spp.) as a cover crop to protect crops from plant-parasitic nematodes. Appl Soil Ecol 46:307-320

Ingels CA (1998). Cover Cropping in Vineyards: A Grower's Handbook, Vol. 3338, pp:113-125. University of California, Agriculture and Natural Resources

López-Pérez JA, T Roubtsova, MDC García, A Ploeg (2010). The potential of five winter-grown crops to reduce root-knot nematode damage and increase yield of tomato. J Nematol 42:120-127

Marahatta SP, KH Wang, BS Sipes, CR Hooks (2012). Effects of Tagetes patula on active and inactive stages of root-knot nematodes. $J$ Nematol 44:26-30

Marles RJ, JB Hudson, EA Graham, C Soucy-Breau, P Morand, RL Compadre, CM Compadre, GH Towers, JT Arnason (1992). Structure-activity studies of photoactivated antiviral and cytotoxic tricyclic thiophenes. Photochem Photobiol 56:479-487

Natarajan N, A Cork, N Boomathi, R Pandi, S Velavan, G Dhakshnamoorthy (2006) Cold aqueous extracts of African marigold, Tagetes erecta for control tomato root knot nematode, Meloidogyne incognita. Crop Prot 25:1210-1213

Ploeg AT (2002). Effects of selected marigold varieties on root-knot nematodes and tomato and melon yields. Plant Dis 86:505-508

Siddiqui MA, AM Mashkoor (1988). Studies on the nemato-toxicity of root exudates of certain species of Tagetes. Ind J Nematol 18:335-337

Steiner G (1941). Nematodes parasitic on and associated with roots of marigolds (Tagetes hybrids). Proc Biol Soc Washington 54:31-34

Tang CS, CC Young (1982). Collection and Identification of alielopathic compounds from the undisturbed root system of bigalta limpograss (Hemarthria altissima). Plant Physiol 69:155-160

Thies JA, SB Merrill, EL Corley (2002). Red food coloring stain: New, safer procedures for staining nematodes in roots and egg masses on root surfaces. J Nematol 34:179-181

Wang C, S Lower, VM Williamson (2009). Application of Pluronic gel to the study of root-knot nematode behaviour. Nematology 11:453-464

Wang KH, C Hooks, A Ploeg (2007). Protecting crops from nematode pests: Using marigold as an alternative to chemical nematicides. Plant Dis 35:6

Wang X, Li GH, CG Zou, XL Ji, T Liu, PJ Zhao, LM Liang, JP Xu, ZQ An, X Zheng, YK Qin (2014). Bacteria can mobilize nematode-trapping fungi to kill nematodes. Nat Commun 5; Article 5576 